\title{
Pengaruh Variasi Konsentrasi Ekstrak Temugiring (Curcuma heyneana) dalam Sediaan Krim terhadap Nilai SPF
}

\author{
Anisa Lailatusy Syarifah ${ }^{1 *}$, Andini ${ }^{1}$, Haritsah Alfad ${ }^{1}$, dan Auril Alfurida ${ }^{1}$ \\ ${ }^{1}$ Akademi Farmasi Putra Indonesia Malang, Indonesia \\ *Corresponding Author. E-mail: nisa17.as@gmail.com
}

\begin{abstract}
Temugiring (Curcuma heyneana) contains flavonoid and curcumin compounds that have the potential as sunscreen. Therefore, the extract concentration added in the cream formulation must be determined precisely since it may affect the Sun Protection Factor (SPF) value. This research aims to determine the effect of concentration variations of temugiring extract on the SPF value of the temugiring extract cream. In this research, ethanol extract temugiring were obtained by maceration employing ethanol. Then, temugiring extract obtained was formulated in cream formulations with variations in the extract concentration 5\%, 7.5\%, and 10\%. Furthermore, the $S P F$ value was conducted using the UV-Vis spectrophotometry method. The results show that concentration variations of temugiring

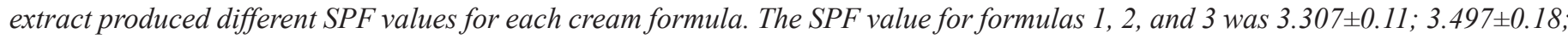
$4.966 \pm 0.24$. Therefore, it can be concluded that the concentration variations of temugiring extract affect the SPF value and creams with concentrations of temugiring extract 5\%; 7.5\%; and 10\% have the potential as sunscreens with minimal until moderate categories.
\end{abstract}

Keywords: Curcuma heyneana, cream, sun protection factor, temugiring

\section{ABSTRAK}

Temugiring (Curcuma heyneana) mengandung senyawa flavonoid dan kurkumin yang berpotensi sebagai tabir surya, sehingga konsentrasi ekstrak yang ditambahkan dalam formulasi sediaan krim harus ditentukan secara tepat karena akan berpengaruh terhadap nilai Sun Protection Factor (SPF). Tujuan penelitian ini adalah mengetahui pengaruh variasi konsentrasi ekstrak temugiring terhadap mutu fisik dan nilai SPF krim. Dalam penelitian ini, ekstrak temugiring diperoleh dari metode maserasi menggunakan pelarut etanol 96\%, kemudian diformulasikan dalam sediaan krim dengan variasi konsentrasi ekstrak 5\%; 7,5\%; dan 10\%. Selanjutnya, penentuan nilai SPF dilakukan dengan metode spektrofotometri UV-Vis. Hasil penelitian menunjukkan variasi konsentrasi ekstrak temugiring menyebabkan nilai SPF yang berbeda pada setiap formula. Nilai SPF formula 1, 2, dan 3 adalah 3,307 $\pm 0,11 ; 3,497 \pm 0,18 ; 4,966 \pm 0,24$. Dengan demikian, dapat disimpulkan bahwa variasi konsentrasi ekstrak temugiring akan berpengaruh terhadap nilai SPFnya dan krim dengan konsentrasi ekstrak temugiring 5\%,7,5\%, dan 10\% berpotensi sebagai tabir surya dengan kategori minimal hingga sedang.

Kata Kunci: Curcuma heyneana, krim, sun protection factor, temugiring

Submitted: December $16^{\text {th }} 2021 \mid$ Accepted: December 27th 2021| Published: December $31^{\text {st }} 2021$

\section{Pendahuluan}

Paparan sinar ultraviolet (UV) mempunyai beberapa manfaat, salah satunya untuk membantu proses sintesis vitamin $\mathrm{D}$ di dalam tubuh dan membantu proses fotosintesis pada tumbuhan. Namun, disamping efek menguntungkan, paparan sinar matahari memberikan dampak merugikan pada tubuh manusia bergantung pada panjang gelombang dan frekuensi paparan, intensitas sinar matahari, dan sensitivitas individu yang terpapar [1]. Paparan sinar UV yang berlebih dapat mengakibatkan hiperpigmentasi, penuaan dini, bahkan kanker kulit [2]. Salah satu cara untuk mengatasi masalah yang ditimbulkan dari bahaya paparan sinar UV adalah dengan penggunaan tabir surya [3]. Tabir surya (sunscreen) adalah bahan yang dapat mengabsorbsi, memantulkan, dan menghamburkan radiasi UV sehingga dapat menjaga kulit dari efek yang membahayakan [4]. Senyawa metabolit sekunder yang berpotensi sebagai tabir surya adalah senyawa fenolik [5].
Senyawa fenolik berpotensi sebagai tabir surya karena memiliki gugus kromofor yang mampu menyerap sinar UV, baik UV A dan UV B, sehingga dapat mengurangi intensitas radiasi UV yang mengenai kulit. Beberapa senyawa yang telah dilaporkan memiliki kemampuan sebagai pelindung terhadap sinar UV antara lain flavonoid, tanin, antrakuinon, dan sinamat [5]. Bahan aktif tabir surya dapat diperoleh dari bahan alam [6] seperti dari rimpang temugiring (Curcuma heyneana). Berdasarkan penelitian Kristianto, et al. (2020), rimpang temugiring mengandung golongan senyawa polifenol, kurkumin, dan polifenol [7].

Rimpang temugiring mengandung senyawa kurkumin [8], yang berpotensi sebagai tabir surya. Sesuai penelitian Kusumawati, et al. (2018), aktivitas antioksidan ekstrak temugiring ditentukan secara in vitro menggunakan DPPH, diperoleh nilai IC50 $338.18 \pm 8.17 \mu \mathrm{g} / \mathrm{mL}$. Dalam penelitian tersebut diketahui bahwa konsentrasi kurkumin mempunyai korelasi dengan aktivitas antioksidan ekstrak temugiring. 
Hal ini menunjukkan bahwa ekstrak temugiring mengandung senyawa kurkumin yang berpotensi sebagai antioksidan dan sebagai kandidat dalam phytocosmeceutical [9]. Dengan demikian, rimpang temugiring berpotensi sebagai bahan aktif sediaan tabir surya.

Tabir surya dapat dibuat dalam sediaan krim. Krim merupakan bentuk sediaan setengah padat yang mengandung satu atau lebih bahan obat terlarut atau terdispersi dalam bahan dasar yang sesuai. Tipe krim dibedakan menjadi dua tipe, yaitu tipe krim minyak dalam air (M/A) dan air dalam minyak (A/M). Efektifitas sediaan tabir surya ditunjukkan berdasarkan nilai Sun Protection Factor (SPF). Penentuan nilai SPF secara in vitro dilakukan dengan metode spektrofotometri UV-Vis sesuai dengan persamaan Mansur [10]. Penambahan ekstrak dalam formula sediaan krim sangat berpengaruh terhadap mutu fisik sediaan. Sedangkan konsentrasi ekstrak dalam formulasi harus ditentukan dengan tepat agar dapat berfungsi sebagai zat aktif sesuai dengan penggunaannya.

Berdasarkan uraian di atas, penelitian ini bertujuan untuk menentukan pengaruh variasi konsentrasi ekstrak rimpang temugiring terhadap nilai SPF krim.

\section{Bahan dan Metode Bahan}

Tanaman yang digunakan dalam penelitian ini adalah rimpang temugiring (Curcuma heyneana) yang diperoleh dan dideterminasi di UPT Materia Medica, Batu, Jawa Timur dengan nomor surat 074/562/102.7-A/2021. Bahan pelarut dan reagen yang digunakan antara lain etanol absolute pro analis (Fulltime), etanol 96\% teknis (PT. Brataco), magnesium powder, besi (III) klorida, asam klorida, asam borat dengan grade pro analyst (Merck). Asam stearat, paraffin, cetyl alcohol, triethanolamine (TEA), cera alba, nipasol, propilen glikol, nipagin, dan aquadest (PT. Brataco).

\section{Instrumen}

Alat yang digunakan dalam penelitian ini adalah peralatan gelas, neraca digital, oven (Memmert), $\mathrm{pH}$ meter, pipet volume, kaca preparate, waterbath, rotary evaporator vakum, cawan porselin, aluminium foil, desikator, kertas saring Whatmann No. 40, dan spektrofotometer UV-Vis (Thermo Fisher Scientific - Genesys 10S Uv-Vis / Model G10S UV-Vis).

\section{Pembuatan Ekstrak Etanol Temugiring}

Serbuk simplisia rimpang temugiring sebanyak 800 g dimaserasi (3 x 24 jam) dengan etanol 96\% sebanyak 8 liter. Filtrat yang diperoleh kemudian diuapkan pelarutnya menggunakan rotary evaporator vakum hingga diperoleh ekstrak kental [11].

\section{Skrining Fitokimia}

Identifikasi senyawa senyawa tanin dilakukan dengan cara $0,5 \mathrm{~g}$ ekstrak dilarutkan dalam $10 \mathrm{ml}$ aquadest kemudian disaring. Filtrat yang diperoleh kemudian ditambahkan 2-3 tetes larutan $\mathrm{FeCl} 3$ 3\%. Adanya senyawa tanin ditandai dengan terbentuknya warna hijau biru hingga kehitaman. Identifikasi senyawa flavonoid dilakukan dengan cara $2 \mathrm{~mL}$ ekstrak direaksikan dengan 0,5 $\mathrm{mL} \mathrm{HCl} \mathrm{36 \%} \mathrm{dan} \mathrm{0,5} \mathrm{g} \mathrm{serbuk}$ $\mathrm{Mg}$. Adanya flavonoid ditandai dengan terbentuknya warna merah tua (magenta) [12]. Identifikasi senyawa kurkumin dilakukan dengan cara $2 \mathrm{~mL}$ ekstrak direaksikan dengan boric acid solution 5\% (asam borat dan asam sitrat masing-masing 5\% dalam methanol). Adanya kurkumin ditandai dengan terbentuknya warna kuning atau merah kecoklatan [8].

\section{Pembuatan Krim Ekstrak Etanol Temugiring}

Pembuatan krim dilakukan dalam skala kecil di laboratorium, yaitu dengan cara asam stearate, paraffin, setil alcohol, trietanolamin (TEA), cera alba, dan nipasol (fase minyak) dimasukkan dalam cawan porselen kemudian dipanaskan pada temperature $70 \mathrm{oC}$, sedangkan propilen glikol dan nipagin (fase air) dalam beaker glass dilarutkan dengan air panas. Selanjutnya, fase minyak dipindahkan ke dalam mortir yang telah dipanasksn sebelumya, kemudian fase air dimasukkan sedikit demi sedikit ke dalam campuran fase minyak yang ada di dalam mortir panas sambil terus diaduk. Campuran fase air dan fase minyak terus diaduk konstan hingga terbentuk massa krim. Setelah terbentuk krim dan mencapai suhu ruang, kemudian ekstrak etanol temugiring dimasukkan sedikit demi sedikit ke dalam basis krim sambil terus diaduk hingga homogen. Formula krim dengan variasi konsentrasi ditunjukkan pada Tabel 1 [11].

Tabel 1. Formulasi Sediaan Krim Ekstrak Etanol Temugiring [11]

\begin{tabular}{lccc}
\hline \multicolumn{1}{c}{ Bahan } & $\begin{array}{c}\text { F1 } \\
(\mathbf{\%})\end{array}$ & $\begin{array}{c}\text { F2 } \\
\mathbf{( \% )}\end{array}$ & $\begin{array}{c}\text { F3 } \\
\mathbf{( \% )}\end{array}$ \\
\hline $\begin{array}{l}\text { Ekstrak temu- } \\
\text { giring }\end{array}$ & 5,00 & 7,50 & 10,00 \\
Parafin liquid & 5,00 & 5,00 & 5,00 \\
Nipasol & 0,02 & 0,02 & 0,02 \\
Nipagin & 0,12 & 0,12 & 0,12 \\
Propilen glikol & 20,00 & 20,00 & 20,00 \\
TEA & 2,00 & 2,00 & 2,00 \\
Asam stearat & 5,00 & 5,00 & 5,00 \\
Asetil alkohol & 2,00 & 2,00 & 2,00 \\
Cera alba & 20,00 & 20,00 & 20,00 \\
Aquadest & ad $100 \mathrm{ml}$ & ad $100 \mathrm{ml}$ & ad $100 \mathrm{ml}$ \\
\hline
\end{tabular}

\section{Uji Mutu Fisik Sediaan Krim Ekstrak Etanol Temugiring}

Uji organoleptis dilakukan dengan cara diambil krim secukupnya kemudian diletakkan di atas kaca preparat. Selanjutnya diamati bau, warna, dan teksturnya. Uji homogenitas dilakukan dengan cara diambil krim secukupnya kemudian diletakkan di atas objek glass dan bagian atasnya ditutup dengan cover glass. Selanjutnya diamati homogenitasnya. Uji daya sebar dilakukan dengan cara diletakkan krim di tengah objek glass sebanyak 0,5 gram kemudian bagian atasnya ditutup dan ditambahkan beban secara bergantian, mulai dari 50, 100, 150, 200, dan 250 g. Selanjutnya didiamkan selama 1 menit dan diukur diameter krim yang menyebar. Uji pH dilakukan dengan cara $1 \mathrm{~g}$ ekstrak diencerkan dengan $10 \mathrm{~mL}$ aquadest. Selanjutnya dilakukan pengukuran $\mathrm{pH}$ menggunakan $\mathrm{pH}$ meter. Sediaan yang baik dan tidak mengiritasi harus memiliki pH krim tabir surya, yaitu 6-9 [13]. Uji tipe krim dilakukan dengan metode pengenceran, yaitu dengan cara melarutkan krim ke dalam air dan minyak. Jika krim dapat larut dalam air, maka krim termasuk krim o/w, sebaliknya jika krim dapat larut dalam minyak, maka krim tersebut termasuk krim w/o.

\section{Penentuan Nilai SPF}

Penentuan nilai SPF dilakukan dengan cara membuat larutan uji dengan konsentrasi 1000 ppm, yaitu masing-masing krim ekstrak etanol temugiring dengan variasi konsentrasi ekstrak $5 \%, 7,5 \%$, dan $10 \%$ ditimbang sebanyak $0,025 \mathrm{~g}$ 
ditambahkan etanol pro analis sebanyak $25 \mathrm{~mL}$, sehingga diperoleh larutan uji dengan konsentrasi 1000 ppm. Selanjutnya, dapat ditentukan nilai absorbansi larutan uji dengan panjang gelombnag 290 - 320 ppm [14].

Untuk mengetahui pengaruh penambahan konsentrasi ekstrak etanol temugiring terhadap nilai SPF, maka data nilai SPF yang diperoleh dianalisis dengan uji statistik menggunakan uji varian satu arah One Way Anova. Untuk menghitung nilai SPF berdasarkan persamaan Mansur [15]:

$$
\begin{aligned}
& \mathrm{SPF}=\mathrm{CF} \times \sum_{2 \infty 0}^{320} E E \quad(\lambda) \times \text { absorbansi }(\lambda) \\
& \mathrm{CF}=\text { Faktor Korelasi }(10) \\
& \mathrm{EE}=\text { Spektrum Efek Eritema } \\
& \mathrm{I}=\text { Spektrum Intensitas Cahaya } \\
& \text { Abs = Absorbansi sampel tabir surya }
\end{aligned}
$$

Nilai EE x I adalah konstanta. Nilainya dari panjang gelombang 290-320 nm dan setiap selisih $5 \mathrm{~nm}$ telah ditentukan seperti Tabel 2 dan keefektifan tabir surya berdasarkan nilai SPF dapat dilihat pada Tabel 3.

Tabel 2. Nilai Spektrum Efek Eritema-Intensitas Cahaya (EE x I) [14]

\begin{tabular}{cc}
\hline $\begin{array}{c}\text { Panjang Gelombang } \\
(\mathbf{n m})\end{array}$ & Nilai EE x I \\
\hline 290 & 0,015 \\
295 & 0,0817 \\
300 & 0,2874 \\
305 & 0,3278 \\
310 & 0,1864 \\
315 & 0,0839 \\
320 & 0,018 \\
\hline Total & $\mathbf{1}$ \\
\hline
\end{tabular}

Tabel 3. Keefektifan Tabir Surya [2]

\begin{tabular}{cc}
\hline SPF & Kategori Proteksi Tabir Surya \\
\hline $2-4$ & Proteksi minimal \\
$4-6$ & Proteksi sedang \\
$6-8$ & Proteksi ekstra \\
$8-15$ & Proteksi maksimal \\
15 & Proteksi ultra \\
\hline
\end{tabular}

\section{Hasil dan Pembahasan}

\section{Ekstrak Etanol Rimpang Temugiring}

Ekstrak etanol rimpang temugiring yang diperoleh berupa cairan kental berwarna kuning-coklat tua yang ditunjukkan pada Gambar 1a. Dalam penelitian ini, metode maserasi dipilih sebagai metode ekstraksi bertujuan agar senyawa yang tidak tahan terhadap pemanasan suhu tinggi tetap stabil dan konsentrasinya tidak berkurang [16]. Selanjutnya, dalam metode ekstraksi tersebut, digunakan etanol 96\% karena senyawa yang berpotensi sebagai tabir surya, seperti flavonoid dan kurkumin mempunyai kelarutan yang rendah terhadap senyawa hidrokarbon dan mudah larut dalam etanol. Flavonoid dan kurkuminoid memiliki sejumlah gugus $\mathrm{OH}$ yang terikat pada cincin aromatiknya, sehingga bersifat polar dan larut dalam etanol [8].

\section{Skrining Fitokimia Ekstrak Etanol Rimpang Temugiring}

Hasil skrining senyawa tanin, flavonoid, dan kurkumin, menunjukkan bahwa ekstrak etanol temugiring positif mengandung senyawa tanin, flavonoid, dan kurkumin. Adanya senyawa flavonoid ditunjukkan dengan terbentuknya warna merah - kecoklatan (magenta), adanya senyawa tanin ditunjukkan dengan terbentuknya warna hitam kebiruan, dan adanya senyawa kurkumin ditunjukkan dengan adanya warna orange. Gambar hasil skrining fitokimia ditunjukkan pada Gambar 1b.

\section{Mutu Fisik Sedian Krim Ekstrak Etanol Rimpang Temugiring}

Pemeriksaan mutu fisik meliputi organoleptis, homogenitas, $\mathrm{pH}$, daya sebar, tipe krim, dan nilai SPF. Hasil pengamatan organoleptis krim ekstrak etanol temugiring disajikan pada Tabel 4. Hasil uji organoleptis menunjukkan bahwa ketiga sediaan krim yang dibuat memiliki bentuk semisolid. Warna yang dihasilkan yaitu kuning untuk F1, kuning kecoklatan untuk F2, dan coklat untuk F3 (Gambar 1c). Dari hasil yang diperoleh diketahui bahwa semakin tinggi konsentrasi temugiring maka semakin pekat warna yang dihasilkan. Krim F1, F2, dan F3 memiliki bau khas temugiring. Warna kuning - kecoklatan dari sediaan disebabkan oleh penambahan ekstrak etanol rimpang temugiring. Aroma yang dihasilkan oleh krim ekstrak etanol temugiring bergantung dari konsentrasi ekstrak yang ditambahkan dalam sediaan krim. Semakin tinggi konsentrasi ekstrak maka aroma yang dihasilkan semakin kuat, dari ketiga formula yang paling kuat aroma khas temugiring yaitu formula 3.

Tabel 4. Organoleptis Krim Ekstrak Etanol Temugiring

\begin{tabular}{cccc}
\hline \multirow{2}{*}{ Sampel } & \multicolumn{3}{c}{ Hasil Organoleptis } \\
\cline { 2 - 4 } & Bentuk & Warna & Bau \\
\hline F1 & semisolid & Kuning & temugiring \\
F2 & semisolid & Kuning - coklat & temugiring \\
F3 & semisolid & Coklat & temugiring \\
\hline
\end{tabular}

Tabel 5. pH Krim Ekstrak Etanol Temugiring

\begin{tabular}{cccc}
\hline \multirow{2}{*}{ Replikasi } & \multicolumn{3}{c}{$\mathbf{p H}$} \\
\cline { 2 - 4 } & $\mathbf{F 1}$ & $\mathbf{F 2}$ & $\mathbf{F 3}$ \\
\hline 1 & 7,21 & 7,65 & 6,98 \\
2 & 6,54 & 7,37 & 6,79 \\
3 & 7,00 & 7,60 & 6,11 \\
\hline $\begin{array}{c}\text { Rata-rata } \\
\pm \text { SD }\end{array}$ & $6,917 \pm 0,28$ & $7,540 \pm 0,12$ & $6,627 \pm 0,37$ \\
\hline
\end{tabular}

Uji homogenitas dilakukan untuk memastikan bahwa semua bahan, baik fase air, fase minyak, dan ekstrak telah tercampur homogen, sehingga apabila diaplikasikan ke bagian kulityang membutuhkan terapi/obat, maka bagian kulitmemiliki kesempatan yang sama untuk mendapatkan khasiat dari zat yang terkandung pada formula krim. Seluruh krim tercampur homogen dengan tidak adanya partikel kasar pada kaca objek.

Pengujian $\mathrm{pH}$ dilakukan untuk menentukan $\mathrm{pH}$ krim yang dibuat sudah sesuai dengan $\mathrm{pH}$ kulit. Sesuai dengan penelitian Sopyan, et al., 2018 [3], secara umum pH krim tabir surya adalah 6-9. Berdasarkan data Tabel 5, diketahui bahwa $\mathrm{pH}$ krim ekstrak temugiring adalah $6,627 \pm 0,37-7,540 \pm 0,12$. Berdasarkan data Tebel 5, diketahui bahwa $\mathrm{pH}$ krim cenderung sedikit asam. Hal ini disebabkan karena ekstrak temugiring 


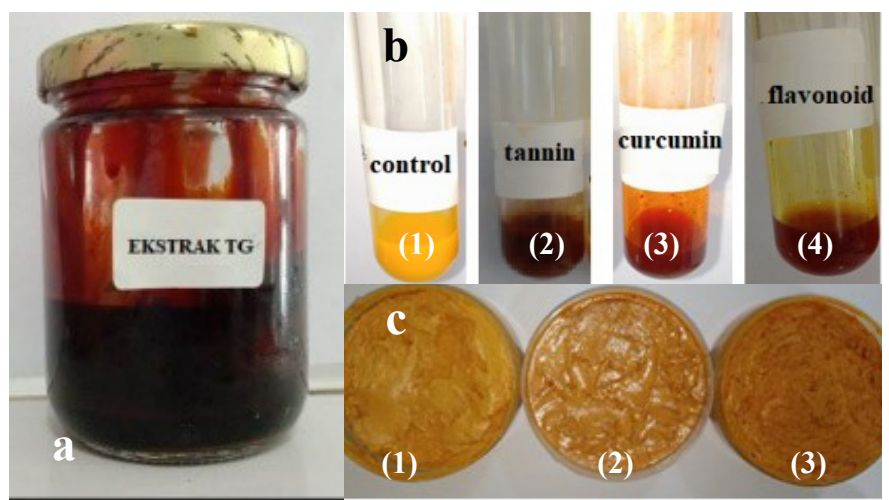

Gambar 1. Ekstrak etanol rimpang temugiring (a); Hasil skrining fitokimia ekstrak temugiring (b) [Keterangan pereaksi: (1)Kontrol, (2)

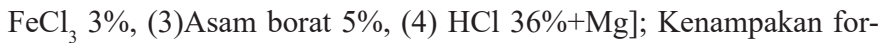
mula krim temugiring F1, F2, F3 (c)

memiliki $\mathrm{pH}$ asam. Semakin banyak konsentrasi ekstrak yang ditambahkan maka semakin asam $\mathrm{pH}$ krim yang dihasilkan. Hal ini dibuktikan dengan analisis data menggunakan SPSS, nilai $\mathrm{pH}$ pada setiap formula terdistribusi normal $(\mathrm{p}>0.05)$ dan dilakukan uji one way ANOVA diperoleh nilai $\mathrm{p}<0.05$ yaitu $\mathrm{p}=0,042$, sehingga dapat disimpulkan bahwa ada perbedaan yang signifikan antara peningkatan konsentrasi terhadap $\mathrm{pH}$ sediaan krim. Namun, pH sediaan krim masih sesuai dengan standar krim tabir surya dan tidak terlalu basa. Krim yang memiliki $\mathrm{pH}$ terlalu basa akan menyebabkan kulit bersisik sedangkan jika $\mathrm{pH}$ terlalu asam akan menimbulkan iritasi.

Tabel 6. Daya Sebar Krim Ekstrak Temugiring dengan Beban 250 g

\begin{tabular}{cccc}
\hline \multirow{2}{*}{ Replikasi } & \multicolumn{3}{c}{ Daya Sebar $(\mathbf{c m})$} \\
\cline { 2 - 4 } & F1 & F2 & F3 \\
\hline 1 & 5,40 & 5,61 & 5,95 \\
2 & 5,00 & 5,72 & 5,65 \\
3 & 5,75 & 5,97 & 5,20 \\
\hline Rata-rata & $5,38 \pm 0,31$ & $5,77 \pm 0,15$ & $5,60 \pm 0,31$ \\
\pm SD &
\end{tabular}

Uji daya sebar dilakukan untuk mengukur daya sebar krim pada permukaan kulit yang dioleskan pada kulit tanpa harus menggunakan tekanan yang besar. Kemampuan krim menyebar dengan baik akan memberikan kemudahan saat diaplikasikan pada permukaan kulit. Selain itu penyebaran zat aktif pada kulit akan lebih merata sehingga efek yang ditimbulkan zat aktif lebih optimal. Data hasil pengujian daya sebar dari 3 formula menunjukkan hasil pada rentang 5-5,9cm (Tabel 6). Hal tersebut menunjukkan bahwa krim yang telah dibuat memenuhi syarat daya sebar yaitu 5-7 cm [17]. Selanjutnya, berdasarkan analisis data SPSS, daya sebar pada setiap formula terdistribusi normal $(p>0.05)$ dan setelah dilakukan uji one way ANOVA diperoleh nilai $\mathrm{p}>0.05$, sehingga dapat disimpulkan bahwa tidak ada perbedaan yang signifikan antara peningkatan konsentrasi terhadap daya sebar sediaan krim. Hal ini ditunjukkan pada data daya sebar pada F1, F2, dan F3 setelah diberi beban 250 gram memiliki nilai $\mathrm{p}=0.407$.

Tipe emulsi krim ditentukan dengan dua metode, yaitu metode pengenceran dan pewarnaan. Pada metode pengenceran, krim dilarutkan dalam air dan minyak. Apabila krim dapat larut dalam air, maka tipe emulsi termasuk golongan oil in water o/w. Sebaliknya jika krim tidak dapat larut dalam minyak, maka tipe emulsi termasuk krim w/o. Berdasarkan hasil penelitian, krim dapat larut dalam air. Oleh karena itu, tipe emulsi krim dalam penelitian ini termasuk dalam tipe oil in water o/w. Selanjutnya, penentuan tipe emulsi krim dengan metode pewarnaan juga menunjukkan hasil yang sama yaitu tipe emulsi o/w karena ketika ketiga formula direaksikan dengan metilen blue, terjadi perubahan warna menjadi biru yang menunjukkan bahwa tipe emulsi oil in water. Krim yang dihasilkan memiliki tipe emulsi oil in water $(\mathrm{o} / \mathrm{w})$ atau water in oil (w/o).

\section{Nilai SPF Sediaan Krim Ekstrak Etanol Rimpang Temugiring}

Penentuan nilai SPF dilakukan secara in vitro menggunakan metode spektrofotometri UV-Vis dengan rentang panjang gelombang $290-320 \mathrm{~nm}$. Selanjutnya data absorbansi dari hasil pengukuran diolah menggunakan persamaan Mansur. Pada penelitian ini, nilai Correction Factor (CF) adalah 10 [14,15]. Data nilai SPF krim formula 1, 2, dan 3 pada setiap replikasi ditunjukkan pada Tabel 7 .

Tabel 7. Nilai SPF sediaan krim ekstrak etanol temugiring

\begin{tabular}{cccc}
\hline Sampel & Replikasi & Nilai SPF & Rata-rata \pm SD \\
\hline \multirow{2}{*}{ F1 } & 1 & 3,474 & \\
& 2 & 3,234 & $3,307 \pm 0,12$ \\
& 3 & 3,213 & \\
F2 & 1 & 3,349 & $3,497 \pm 0,18$ \\
& 2 & 3,385 & \\
\hline \multirow{2}{*}{ F3 } & 3 & 3,756 & \\
& 1 & 5,306 & $4,965 \pm 0,24$ \\
\hline
\end{tabular}

Berdasarkan data Tabel 7, diketahui bahwa semakin besar konsentrasi ekstrak maka semakin besar nilai SPF sediaan krim. SPF merupakan indikator universal yang menjelaskan efektivitas suatu produk yang bersifat UV protektor. Peningkatan nilai SPF juga disebabkan karena semakin besar konsentrasi ekstrak temugiring yang ditambahkan dalam sediaan, maka konsentrasi senyawa yang berkontribusi dalam mengabsorbsi sinar UV semakin besar. Sesuai dengan hasil skrining fitokimia, ekstrak etanol temugiring mengandung senyawa flavonoid, fenolik (tanin), dan kurkumin, dimana ketiganya berpotensi sebagai antioksidan dan berguna sebagai bahan aktif yang berpotensi sebagai tabir surya karena adanya gugus kromofor yang mampu menyerap sinar UV, baik UV A dan UV B, sehingga mengurangi intensitas radiasi UV yang sampai pada kulit [18]. FDA mensyaratkan tabir surya yang beredar di pasaran harus memiliki nilai SPF minimal 2. Apabila nilai SPF kurang dari 2, maka tidak memiliki kemampuan untuk melindungi kulit dari sinar matahari atau tidak berpotensi sebagai tabir surya. Hasil yang diperoleh dari ketiga formula krim berturut-turut yaitu $3,307 \pm 0,12 ; 3,497 \pm 0,18$; dan 4,965 $\pm 0,24$. Hasil nilai SPF tersebut menunjukkan bahwa ketiga formula krim memenuhi syarat sebagai tabir surya dengan kategori proteksi minimal. Dalam penelitian ini dilakukan analis data dengan menggunakan SPSS (versi 16 ) untuk menentukan pengaruh penambahan ekstrak etanol rimpang temugiring terhadap nilai SPF krim. Analisis yang digunakan yaitu uji normalitas menggunakan Shapiro-Wilk. Apabila data berdistribusi normal dan homogen dilakukan uji varian satu arah (One Way Anova). Jika data berdistribusi tidak 
normal, maka dilakukan analisis Kruskal-Wallis. Hasil dari uji SPF sediaan krim ekstrak etanol temugiring dilakukan dengan pengulangan sebanyak 3 kali dan berdasarkan uji normalitas menunjukkan bahwa ketiga formula (F1, F2, dan F3), data berdistribusi normal ( $\mathrm{p}$-value $>0,05$ ). Pada uji homogenitas menunjukkan bahwa data homogen ( $p$-value $>0,05$ ) yaitu 0,308. Selanjutnya pada uji One Way Anova menghasilkan p-value $<0,05$ maka H0 ditolak dan H1 diterima yang berarti ada pengaruh penambahan variasi konsentrasi ekstrak etanol temugiring terhadap nilai SPF krim. Dengan demikian, dapat disimpulkan bahwa dalam ekstrak etanol rimpang temugiring mengandung senyawa yang berpotensi dalam meningkatkan nilai SPF.

\section{Kesimpulan}

Konsentrasi ekstrak etanol temugiring berpengaruh terhadap $\mathrm{pH}$ dan nilai SPF sediaan krim dan tidak mempengaruhi organoleptis, homogenitas, serta daya sebar sediaan krim. Nilai SPF sediaan krim untuk formula 1, 2, dan 3 secara berurutan adalah $3,307 \pm 0,12 ; 3,497 \pm 0,18$; dan $4,965 \pm 0,24$.

\section{Ucapan Terima Kasih}

Peneliti mengucapkan terima kasih kepada Kementrian Pendidikan, Kebudayaan, Riset, dan Teknologi Republik Indonesia atas dana penelitian yang diberikan dalam skim Penelitian Dosen Pemula Tahun Pelaksanaan 2021.

\section{Daftar Pustaka}

[1] Amnuaikit Thanaporn and Boonme Prapaporn. Formulation and characterization of sunscreen creams with synergistic efficacy on SPF by a combination of UV filters. Journal of Applied Pharmaceutical Science. 2020; 3 (08): 001-005

[2] Damogalad, V., Hosea J. E., Hamidah, S. S., Formulasi krim tabir surya ekstrak kulit nanas (Ananas comosus L. Merr) dan uji in vitro nilai Sun Protecting Factor (SPF). Pharmacon Jurnal Ilmiah Farmasi - Unsrat. 2013; (13)(2): 02: $39-44$

[3] Rejeki S, Wahyuningsih SS. Formulasi gel tabir surya minyak nyamplung (Tamanu Oil) dan uji nilai SPF secara in vitro. Universitas Research Colloquim. 2015; 97-103.

[4] Sopyan, Iyan, Dolih Gozali, Sylvia Tiassetiana. (2018). Formulation of tomato extracts (Solanum lycopersicum L.) as a sunscreen lotion. National Journal of Physiology, Pharmacy, and Pharmacology. 8(3), 453-458

[5] Subchan, P., Malik DA, Namason WT. Fotoproteksi. MDVI. 2011. 38(3): 141-8

[6] Ayuningrum. Uji stabilitas fisik dan penentuan nilai SPF (Sun Protection Factor) krim tabir surya ekstrak kulit buah papaya (Carica papaya L.).[Artikel]. Ungaran:Sekolah Tinggi Kesehatan Ngudi Waluyo Ungaran. 2016.

[7] Kristianto, S., Jati Batoro, Sri Widyarti, and Sutiman Bambang Sumitro. Exploration and economic value of medicinal plants as traditional herbal ingredients in Bangselok, Madura, Indonesia. Proceding of the 5th NA International Conference on Industrial Engineering and Operations Management Detroit, Michigan, USA. August 10-14, 2020; 3895-3902.
[8] Syarifah1, Anisa Lailatusy, Rurini R, Hermin S. Characterization of the curcuminoids fingerprints profile in curcuma and zingiber genera by TLC-digital image analysis. J. Pure App. Chem. Res. 2019; 8 (2): 147-161

[9] Kusumawati I, Kresma OK, Subhan R, Tri AP, Retno W, Juni E, et al. Anti-aging properties of Curcuma heyneana Valeton\&Zipj: A scientific approach to its use in Javanese tradition. Journal of Ethnopharmacology. 2018: [28 p.]

[10]Souza J.F., F.P. Campos, G.R. Packer, Determinação da atividade fotoprotetora e antioxidante em emulsões contendo extrato de Malpighia glabra L. Acerola, Rev. Ciên. Fram. Básic Apl.. 2013; 34 (1): 69-77.

[11] Lumentut, Natalia., Hosea Jaya Edy, Erladys Melindah Rumondor. Formulasi dan Uji Stabilitas Fisik Sediaan Krim Ekstrak Etanol Kulit Buah Pisang Goroho (Musa acuminafe L.) Konsentrasi $12,5 \%$ sebagai Tabir Surya. Jurnal MIPA. 2020; 9(2), 42-46

[12] Syarifah2, Anisa Lailatusy, Rurini Retnowati, Soebiantoro. Characterization of Secondary Metabolites Profile of Flavonoid from Salam Leaves (Eugenia polyantha) Using TLC and UV-Spectrophotometry. Pharmaceutical Sciences and Research. 2019; 6(3), 155-163

[13] Pratama, G, R. Yanuarti, A. F. Ilhamdy, M.P. Suhana. Formulation of sunscreen cream from Eucheuma cottonii and Kaempferia galanga (zingiberaceae). IOP Conference Series : Earth and Environmental Science. 2019; 278 (pp. 1-7).

[14] Noviardi, Harry, Devi Ratnasari, Muhammad Fermadianto, Formulasi Sediaan Krim Tabir Surya dari Ekstrak Etanol Buah Bisbul (Diospyrus blancoi). Jurnal Ilmu Kefarmasian Indonesia. 2019; 17 (2): 262-271.

[15] Dutra, Elizângela Abreu, Daniella Almança Gonçalves da Costa e Oliveira, Erika Rosa Maria KedorHackmann*, Maria Inês Rocha Miritello Santoro. Determination of Sun Protection Factor (SPF) of Sunsreen by Ultraviolet Spectrophotometry. Brazilian Journal of Pharmaceutical Sciences, 2004; 40, 381-385.

[16] Wonorahardjo, Surjani. 2016. Metode-Metode Pemisahan Kimia. Jakarta. Indeks

[17] Rahmawati, D., Dan Fadhilaturrahmah. 2014. Studi Aktivitas Tabir Surya Buah Limpasu (Baccaurea Lanceolata) Berdasarkan Penentuan Nilai Sun Protection Factor (SPF) Secara In Vitro, Journal Of Pharmascience, 1(1), $55-58$.

[18] Hogade, M.G., Basawaraj, S.P., \& Dhumal, P. (2010). Comparative Sun Protection Factor Determination of Fresh Fruits Extract of Cucumber vs Marketed Cosmetic Formulation, Research Journal of Pharmaceutical, Biological and Chemical Science, 1 (3), 55-99 